\title{
La animación sociocultural en los centros penitenciarios
}

La animación sociocultural en los centros penitenciarios tiene un afán noble: renovar y promocionar al interno como persona y ponerle en contacto con la sociedad para intensificar la vida social que será el punto de su destino.

\section{Por Ciriaco IZQUIERDO MORENO*}

\section{Introducción}

La animación sociocultural (a.s.c.) en el medio penitenciario tiene una importancia primordial para romper el tedio y abrir cauces más humanizadores del habitat carcelario, asi como debe servir para despertar inquietudes de cara a vivir con estilo más personal. Hay que luchar para que no sucumba la persona y para que se levante si se encuentra hundida por las circunstanclas adversas que le ha tocado vivir.

Pero otro objetivo fundamental de la a.s.c. es el preparar al interno a poder disfrutar de su libertad en el medio social. Los diversos inconvenientes de la privación de libertad (aislamiento, problemas psicológicos, separación del medio habitual de trabajo) dan mayor protagonismo a la a.s.c. como medio eficaz para preparar la libertad, por to que la ayuda post-peninteciaria debe comenzar cuando el interno se encuentra aún en prisión.

Los centros penitenciarios deben estar más abiertos al exterior y con más contactos con la vida social tanto local como regional en el campo educativo, laboral, de las actividades deportivas, etc.

La animación sociocultural en el centro penitenciario tiene dos puntos capitales de proyección. Uno hacia el interior: sanear eł ambiente,

* Capelián del Instituto Penitenciario de Litria (Valencia), único de régimen abierto para jóvenes en el Estado Español. 


\section{Ciriaco lzquierdo Moreno}

curar al interno, motivarle a comenzar una vida nueva; y otro hacia el exterior: el crear lazos de comunicación con las instituciones sociales y con las juveniles. Un afán doble: renovar y promocionar al sujeto como persona y ponerle en contacto con la sociedad para intensificar la vida social que será el punto de su destino.

El valor efectivo del tiempo libre en los centros penitenciarios está exigiendo mentes creadoras capaces de penetrar en ese mundo deshumanizado, masificado y de ociosidad permanente para humanizarle con entrega, coraje y sabiduria.

La cárcel agrava la situación de la persona, destruye los valores más ricos del ser humano y se convierte en enclave de alienación, cuando no de violencia, soledad, vagancia, incomprensión y amoralidad e inmoralidad. Es generadora de nuevas y más graves delincuencias. Los jóvenes reclusos aprenden de los que ya no lo son tanto, las técnicas del crimen como los estigmas de la prisión, que perduran gran parte de la vida. En no pocos casos, el interno queda traumatizado para siempre.

La solución no está en la construcción de cárceles de máxima seguridad, que son más seguras pero a veces más inhumanas que las antiguas. Nos hacen falta hombres nuevos bien formados y con ver. dadera vocación penitenciaria, leyes fundamentadas en el valor de la persona y estructuras nuevas.

Ante este panorama desgarrador y desolado no cabe la neutralidad, la indiferencia o la pasividad. Es necesaria la solidaridad comprometida en una eficaz y seria actuación penitenciaria. Conocer al delincuente, tratar con él, acercarnos a él, a su vida y conocer a fondo sus problemas.

Esto nos ha llevado a plantearnos en serio su problema, su personalidad interior, sus estructuras afectivas, su sociabilidad, para con un conocimiento más objetivo y real conseguir un tratamiento más humanizador, capaz de promover la dignificación personal y potenciar todas las cualidades del interno que habian quedado anestesiadas por el "shock» de la cárcel.

Una de las respuestas más sugestivas y esclarecedoras ante esta situación es la a.s.c., que viene a forjar un proyecto global de intervención en el centro penitenciario, coordinando actividades, técnicas y trabajos, pero sobre todo cambios individuales encaminados a un desarrollo personal integral y, en el entorno penitenciario que rodea a esas personas, una transformación social. En el interior de los gru- 
pos se generan unas relaciones interpersonales que permiten a cada miembro (y al grupo como tal) ir satisfaciendo sus necesidades y creciendo como persona y como grupo.

El grupo desarrolla una tarea hacia el exterior, en la línea de partio cipación en la construcción y transformación del interno penitenciario. Es un trabajo institucional en sentido amplio: organizar, regular, crear, etc.. Es procesual y estable, no motiva sólo sino que la motivación debe ser el inicio de un camino a largo plazo; no termina nunca, es continua y es una labor de equipo.

El equipo es el motor del proyecto de animación y será eficaz en la medida en que consiga una acción integrada de todos y proporcione un constante feedback a la intervención de cada una. No se trata de una animación espectáculo, ni de una animación de campañas; se trata de una interacción y participación a través de un enraizamiento (dentro de la vida penitenciaria nada fácil, pero posible al menos en centros de jóvenes) de trabajo, actividades culturales, formativas, deportivas, de tiempo libre, etc... y de una proyección en el exterior, participando en tareas con otros jóvenes a través de una pedagogla activa, civica y socializadora.

La animación sociocultural penitenciaria ha de promover un proyecto educativo que tenga como objetivo último promocionar la dignificación de la persona y la transformación del entorno, considerando el trabajo como un tipo de ocupación para que los jóvenes sigan siendo socialmente aceptados y mantengan los estímulos que hoy en día están vinculados con el empleo remunerado.

Por eso, aparte de que existe una voluntad ocupacional, se precisa una alternativa cultural educativa y política distinta a la que hoy prevalece.

Es preciso un cambio de mentalidad, un cambio cultural muy serio. El trabajo ya no puede ser el concepto clave sobre el que gire la oferta educativa y cultural. El nuevo concepto clave ha de ser el tiempo libre o tiempo para y de la libertad.

El valor efectivo del tiempo libre ha provocado también que la sociología primero y la antropología más tarde se hagan eco de este fenómeno social. La sociologia del ocio comienza a mitad del siglo a tener personalidad propia y a ser un campo de la sociologia con amplias perspectivas de futuro. Las ciencias de la Educación también van acompañando a esta realidad social en su reflexión pedagógica y hoy 


\section{Ciriaco Izquierdo Moreno}

la referencia al tiempo libre y al ocio entra en cualquier planteamiento serio educativo.

El Instituto Penitenciario para Jóvenes de Liria supo integrar desde su fundación este fenómeno social en sus estructuras educativas, tanto dentro del centro como fuera, en contacto con la sociedad. Esta experiencia nos brinda la oportunidad de formular nuevos proyectos de actuación penitenciaria sobre nuevos sujetos, nuevos centros y con nuevos detenidos.

Las razones que nos movieron a iniciar la reflexión en el terreno de la animación sociocultural penitenciaria fundamentalmente fueron dos:

- Dar respuesta a las nuevas demandas de acción educativa y cultural en los centros penitenciarios juveniles.

- Ofrecer un modelo orgánico de dinamización social, frente a otros que presentan la animación sociocultural como acciones vacias de proyecto ideológico y carentes de una acción educativa, donde se trata de un activismo de entretenimiento, sin proyección social y sin preocupación formativa.

\section{Fin de los establecimientos para jóvenes}

\subsection{Objetivos de los centros:}

Dos son los fines: privar al delincuente de su libertad y prepararle para su retorno a la sociedad. Se exige al Centro que prive al delincuente de su libertad, pero es el propio establecimiento el que decide sobre el grado de privación de libertad, v. gr. entre salir a trabajar o estudiar diariamente y no tener derecho a disponer de un transistor, etc..

Otro fin sería el preparar al delincuente para su retorno a la comunidad. La tarea de la Administración penitenciaria no consiste en aumentar la pena, sino estudiar qué puede hacer para ayudar al penado, incluso al sometido a medidas de seguridad muy estrictas, para facilitar el desarrollo de la personalidad del joven mirando a su retorno a la sociedad, ya que por definición los jóvenes están en proceso de formación.

Por tanto, corresponde al Centro Penitenciario asegurar que las influencias en él sean positivas y no negativas durante el intermedio. 


\section{La animación sociocultural en los centros penitenciarios}

Para ello son necesarias las siguientes actuaciones: $1^{\circ}$, perseguir el fin resocializador en todos los casos, porque no podemos saber por adelantado qué delincuentes pueden ser "curados" y quiénes no. $2^{\circ}$, no desanimarse porque la tasa de éxitos sea baja. Es difícll en este campo definir el éxito, ya que no sabemos cómo se hubiera comportado el delincuente sin internamiento.

Este objetivo de la ayuda al delincuente es esencial por tres razones:

a) interesa a la socledad ayudar al delincuente para que se aparte de la delincuencia.

b) interesa al mismo joven; para ello debe tener en el Establecimiento el mismo grado de ayuda que tendría fuera, de su familia, de los servicios sociales, de la Escuela, etc.

c) el personal penitenciario se deshumaiza si abandona el objetivo humanitario, convirtiendo las prisiones en lugares de castigo y de deterioro de la personalidad, en lugar de "puntos de arranque" donde los delincuentes estén de forma transitoria y for" jando su futuro.

La Institución debe esforzarse en utilizar este tiempo para ayudar al interno a su reinserción social.

\subsection{Lo que debe hacer la Institución:}

La institución ha de ofrecer todo aquello que les faltó en la vida libre para lograr una integración social adecuada:

a) debe ofrecer un régimen de vida apto para estimular al enganche del "YO" adolescente y proyectar una filosofía de la vida que coincida con la realidad psicológica de ese yo, de forma que permita al joven situarse dentro de unas perspectivas concretas de porvenir.

b) debe crear un clima apropiado, un estilo de vida, una filosofía del vivir, que ha de resultar para los jóvenes un punto de referencia a su identidad. Es decir, que las personas, estructuras, actividades y costumbres contribuyan a un espíitu animador de la vida, a una dinámica de actividades, a un alegria del vivir y a un optimismo en la convivencia.

c) una organización equilibrada que ofrezca a la vez valores cultu- 


\section{Ciriaco Izquierdo Moreno}

rales, sociales y humanos suceptibles de provocar la adhesión del interno al estilo de la vida del centro en consonancia con la vida social.

d) se les debe proporcionar una conciencia de la situación, conciencia de si mismos, y conciencia de su libertad dentro de los limites de su responsabilidad. Este tema de conciencia será el objetivo clave para preparar su libertad futura.

e) la estancia en la Institución debe provocar en los internos una regeneración, una rehabilitación moral. Estos se adherirán a través de las actividades en que toman parte y a través de los lazos afectivos que contraigan en su realización y participación. Hay como un proceso de identificación con la Institución, borrando la imagen delictiva y carcelaria y afirmando los valores de una vida honrada y civica.

No se puede consentir que el "encarcelamiento" produzca un letargo en toda la vida del hombre, que paralice todas sus actividades y que alli se dedique a vegetar, a ser un número en un almacén corrompido.

f) la pastoral penitenciaria debe dirigirse en primer lugar a atender y cultivar la afectividad. Con frecuencia el ansia de afectividad del joven detenido se estrella con el desamor, tanto por parte de la prisión como por parte de la socledad e incluso de sus allegados. La pastoral, al actuar sobre la afectividad, consigue una satisfactoria expresión de la personalidad. El joven se siente angustiado y necesita desahogarse con alguien que le entienda y sepa interpretar su vida.

La institución debe ofrecer en fin "una seguridad en símismon, confianza para emprender un futuro mejor, despertar un deseo de encontrarse a sí mismos y reorganizar su personalidad, suscitando una colaboración lo más activa posible en su proyecto de resocialización.

\subsection{Lo que debe hacer el interno:}

La rehabilitación moral es la base de toda resocialización; sólo contando con ella se obtiene la uliberación más noble y más íntima, la que redime del yugo y de las cadenas de las pasiones y del pecado, la que obra la interior renovación de la vidan (1).

(1) Izquiezdo Moreno, C; Conferencia en la Asamblea Nacional de Capellanes Penitenciarios en Madrid 1985 «La Pastoral Penitenciaria en el mundo actual". 


\section{La animación sociocultural en los centros penitenciarios}

La rehabilitación moral consiste en la consciente y libre vuelta del reo arrepentido a la conformidad con el orden ético y sus obligaciones.

La rehabilitación religiosa consiste en la liberación de aquella culpa interna, intima, que grava y obliga a la persona del reo delante de Dios, es decir, delante de la suprema y última razón de todo derecho, de toda obligación moral.

La rehabilitación psicológica radica en el abandono y retracción del querer perverso, puesto libre y conscientemente por el "yo" en el acto culpable o delictivo y la renovación del propósito de querer lo recto y bueno.

La rehabilitación jurídica se realiza principalmente en lo intimo de la voluntad del reo, se dirige esencialmente a la autoridad superior, cuyas exigencias respecto a las observaciones de las normas establecidas fueron olvidadas y violadas.

La triple reconciliación: El recluso ha de conseguir una triple reconcillación:

Reconciliación consigo mismo: El interno debe afrontar con valentia y humildad su pasado. Tiene que aceptar el pasado tal cual ha sido. Sólo reconociendo el error se puede corregir.

Reconclliación con Dios: El alejamiento de Dios ha sido con frecuencia la causa del delito. Tiene que establecer con Dios las debidas relaciones religiosas. En último término, ésta es la meta del apostolado penitenciario: conseguir la liberación moral y religiosa del delincuente.

Reconciliación con los hombres: Está en la cárcel porque se enfrentó con los hombres, porque lesionó los derechos, porque quebrantó las leyes sociales, porque perturbó la convivencla. Cuando recupere la libertad debe obrar socialmente.

Hay que trabajar también para que la sociedad se reconcilie a su vez con los presos. El delito es un ataque a la sociedad pero en un porcentaje muy alto, "sobre todo en los jóvenes", han sido ellos antes victima de la sociedad misma. El delito del joven es con frecuencia una respuesta al comportamiento injusto que la sociedad ha tenido con él.

Esto es lo fundamental, la transformación de su personalidad. Naturalmente es preciso darle los medios para ganarse la vida, pero és. te es el aspecto secundario de la rehabilitación. Si primero no se transforma, todo lo que aprenda le servirá para ser un criminal más eficaz, y esto será todo. 


\section{Ciriaco Izquierdo Moreno}

Es muy importante la escuela, ya que su primer fracaso partió de la escuela y no debió ser un fracaso.

Junto a este proceso se encuentra la maduración del interno, que consiste en avanzar y abrirse camino al mundo futuro que se halla afec. tado por el pasado. Madurar es aceptar los obstáculos; es muy dificil en jóvenes inestables y fronterizos. Se ven amenazados por multitud de incitaciones alienadoras. La crisis es inevitable. Para muchos jóvenes el mundo de la familia ha perdido todo su valor, se debe llenar ese vacio para que esos muchachos lleguen a ser autores de su proyecto de vida propio y personal.

\subsection{Relaciones con la sociedad:}

Se deben cultivar y aumentar. Se recomienda la entrada de grupos deportivos, de estudiantes. En los centros abiertos participar en actividades comunitarias, prestar sus instalaciones deportivas, fomentar visitas. Promocionar salidas individuales con grupos juveniles.

La formación profesional recibida en el centro debe proyectarse al campo laboral. El trabajo en este sentido es un elemento socializador de primera magnitud. Pero la formación profesional y el trabajo se deben concebir en una dimensión socializadora y de desarrollo de la personalidad. El trabajo en el exterior es de incalculable valor por lo que significa de acercamiento a la sociedad, por la valoración del mismo sujeto en el mundo laboral, por el cambio de vida y por los vínculos de unión que fortalecen su libertad y su personalidad en contacto con la vida social.

Otro medio es crear nuevas conexiones a través de visitas semanales a familias cercanas, los permisos, las vacaciones y las salidas semanales; todo ello va a ir perfilando la configuración de una personalidad fuerte socialmente por parte del interno.

Los permisos de salida concebidos como "ayuda socialn funcionan adecuadamente, son de corta duración y por alguna razón importante se pueden conceder en cualquier momento de la condena. Los permisos de tratamiento pueden concederse después de un mínimo de permanencia de cuatro meses consecutivos de prisión y de que el interno haya cumplido al menos una cuarta parte de su condena. La duración máxima es de siete dias cada vez.

Los internos pueden obtener igualmente una vez al mes un permiso corto cuando les visite su familia, o para asistir a un partido de fút- 


\section{La animación sociocultural en los centros penitenciarios}

bol o a un concierto, etc.. En este caso acompañado por un funcionario, capellán, asistente social, etc. Asimismo hay visitas informativas de escuelas, asociaciones, instituciones y particulares en las que participan los internos.

Muchos de estos permisos, a pesar de ser instrumentos legales y reconocidos teóricamente, en muchos casos en la práctica no se llevan adecuadamente y no siempre por medios materiales o de personal, sino por defecto de organización y funcionamiento.

Es ideal que la familia participe en estos permisos y se comprometa en la responsabilidad que entraña y que los mismos sirvan para incrementar la vinculación familiar.

Toda esta problemática acentúa una vez más la urgente necesidad de la animación sociocultural en el ámbito penitenciario. El Centro $\mathrm{Pe}$ nitenciario debe ofrecer a toda la población interna oportunidades voluntarias de mejoramiento espiritual, a partir del aprendizaje, del ejercicio de actividades creativas y de la participación en los proyectos que refuercen el sentido de identidad y pertenencia a una sociedad libre, a pesar de encontrarse en un centro penitenciario privado de la libertad. Es interesante que los jóvenes participen y asuman su propio proceso social de cambio y el cambio de actitudes ante las personas y colectividades.

Se trata no sólo de un problema personal sino de una animación del grupo, buscando así una interrelación, que favorezca la acción educativa e integradora. Pero no se trata sólo de mover la voluntad, sino de ofrecer y facilitar los medios para que el desarrollo cultural sea integro e integrador, ya que la promoción social va unida a la promo. ción cultural y sigue la línea de valores que ésta le marca. El cambio de actitudes va unido al descubrimiento de contenidos culturales.

Se trata en el fondo de una animación sociocultural amplia que sea capaz de envolver la vida del interno en toda su plenitud, desde el ángulo personal y desde la dimensión social.

\section{La animación sociocultural en los Centros Penitenciarios}

Es un verdadero reto en el momento actual y una auténtica necesidad y exigencia en los centros de jóvenes. 


\section{Ciriaco Izquierdo Moreno}

\section{1. ¿En qué consiste la animación sociocultural?}

Es una acción grupal de promoción sociał y cultural que se desarrolla en el tiempo libre. Es, en un sentido amplio, educación en el tiempo libre (2).

Educación que cuenta con una concepción propia del desarrollo personal, al que concibe como desarrollo sociocultural.

La animación parte del grupo de personas que inicia un proceso de dinamización cultural, grupo que surge del tedio del Centro Penitenciario, donde se pierde el tiempo soberanamente y donde se llega a la anestesia de la propia voluntad.

De ahi que se deba conquistar de nuevo el sentido del tiempo frente a la desocupación y la ociosidad de la prisión, y hay que buscar la revalorización del tiempo y descubrir los distintos matices que puede tener para cualquier persona y de manera especial para el uprivado de libertad", ya que para él el tiempo tiene una dimensión distinta: es el "tiempo sin tiempon; no cuentan los minutos, ni los segundos ni las horas; de aqui es posible el no hacer, la ociosidad pero el tiempo tiene que abrir otras dimensiones más profundas y reales para los internos. El tiempo libre debe ser creativo, tiempo nuestro que nos permita desarrollar plenamente nuestra imaginación, nuestro cuerpo y nuestras manos. El tiempo liberador, tiempo interior en el que se participa plenamente, es un proceso de liberación total, en el que sale al exterior lo más genuino de la persona; se uniria al tiempo activo. Pero el tiempo guarda en si una dimensión relacional y se extiende a un triple objetivo: consigo mismo, con el medio humano y con el medio físico. Es un tiempo de expresión y comunicación; no se trata de una terapia. Es un tiempo de expresión y comunicación; se trata de una comunicación abierta y espontánea; se trata de vivir a todos los niveles la autovaloración desde nosotros mismos y no comparándonos con los demás. Y ese tiempo va a ser un tiempo de compromiso con nuestra sociedad. El tiempo libre no lo podemos vivir nosotros solos ni para nosotros solos (3).

Pero la animación surge desde una opción personal, opción por la participación en la vida social y por una vivencia creativa del tiem-

(2) Viché González, M; Animación Sociocultural y educación en el tiempo libre, Edit. Victor Orenga, Valencia 1986 pág. 11 y ss.

(3) Sastre García, V.J.; La cultura del ocio implicaciones soclates y eclesiales del fin de semana UPCM (Departamento de Publicaciones Universidad de Comilias, Madrid 1984, pág. 53 y ss.) 


\section{La animación sociocultural en los centros penitenciarios}

po libre. Sin embargo, es necesario un animador juvenil. La animación sociocultural juvenil penitenciaria se hace cada dia más patente en los centros de jóvenes. El animador se convierte en un acompañante del sujeto al que interpela y sobre todo al que ofrece cauces de participación y opciones de gestión creativa de su propia dinámica personal.

Podemos afirmar que la animación sociocultural es una metodología que tiene como finalidad última el cambio social en el medio penitenciario, que potencia un proceso cultural, que promueve en cada informe la capacidad de asumir criticamente su realidad y le capacita para organizarse y transformar la historia personal y comunitaria.

Se trata de una tarea de carácter intencional y, por tanto, como de una lección programada, no arbitraria ni improvisada, que comprende tiempo, objetivos, acciones y medios. Su estilo debe ser critico, en permanente lectura de la realidad, participativa, de camblo hecha en común, reflexiva, dialogante y festiva. Exige un proceso, una acción continuada y una acción comunitaria.

La a.s.c. está llamada a tener amplia repercusión en los medios penitenciarios; es necesario hacer renacer la esperanza y la ilusión en la juventud. Esta es sin duda en el momento actual la única via para lograr el equilibrio interior, la paz, la relajación y la aceptación de los compañeros para llegar a una maduración personal y a una verdadera integración en la vida social.

Estas son las bases también para lograr una animación cristiana de la realidad. Nuestra opción creyente según el Evangelio, que inspira el tipo de hombre y de sociedad que queremos construir, exige que los lugares preferenciales de humanización sean aquellos en los que están y viven los pobres y marginados de nuestra sociedad. Esos ambientes injustamente desfavorecidos, aislados de los dinamismos sociales, sin posibilidades ni medios de participación y desarrollo cultural, son una opción imprescindible para quienes quieren educar libremente en la linea del horizonte utópico del Reino de Dios. En esta li. nea se enmarca toda la euforia del voluntariado cristiano en los centros penitenciarios.

En esa doble dimensión de animación cultural y animación cristiana estuvo presente en Liria desde su creación, pero se intensificó a partir de 1979, con la Promulgación de la Ley Penitenciaria, y ha sido todo un derroche de iniciativas promovidas por la pastoral del centro y por las voluntarias sociales, internas y algunas funcionarias.

Pero, a pesar de todo, creemos que la pieza clave en esta labor debe ser y es la figura del animador sociocultural. 
Ciriaco Izquierdo Moreno

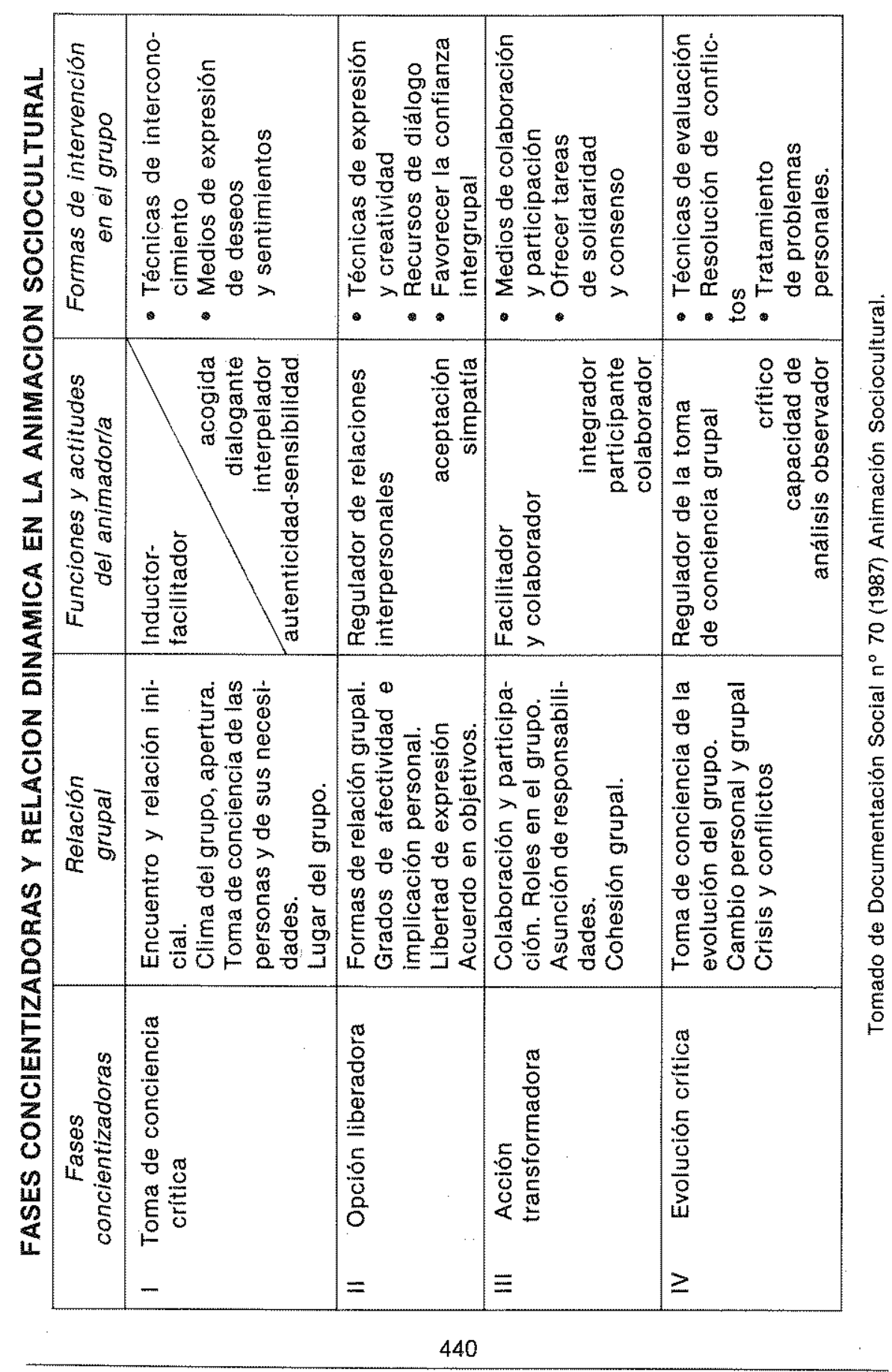


La animación sociocultural en los centros penitenciarios

\subsection{El animador sociocultural:}

La figura del animador juvenll se hace necesaria tanto por su función como por la demanda que hoy existe en el mundo juvenil penitenciario, tan dificil y tan deteriorado en el momento actual (4).

Todas las iniciativas (orientaciones) apuntan a que el animador juvenil no pertenezca al estamento penitenciario, ya que ese animador es un punto de referencia y un portavoz de valores para elevar y dignificar la vida del interno.

Estos animadores juveniles deberían integrarse en el voluntariado que participa en las tareas pastorales; es más, es de ahi de donde deben surgir estos promotores de la animación sociocultural de los tiempos libres.

El animador juvenil debe ser capaz de conectar con la dinámica de los grupos juveniles penitenciarios y con los barrios donde el jo. ven vive la realidad social. Una persona que realice, en sintonia con el joven, una intervención de tipo socioeducativa, que sea capz de generar, en su diálogo con los colectivos jóvenes, acciones y actitudes de inserción crítica en el tejido social.

El animador que trabaje en esta linea ha de tener una visión muy amplia de la problemática y situaciones que vive la juventud carcelaria: situaciones de desamparo, de convivencia, relación personal, famillar y de otros factores que intervienen en la dinámica juvenil. Así la animación sociocultural se convierte en una intervención educativa en el mundo del joven, intentando favorecer que éste tome decisiones libres y creativas ante sus propios problemas. No se trata de ofrecer un servicio de ocupación del tiempo libre; es algo más, más dinámico y más educativo.

Pero son necesarias las actividades que se entronquen, tanto en el interior del centro y en el exterior. Esas actividades deben ser capaces de motivar y, después de provocar la participación.

El animador debe tener gusto y sentido del contacto y de la comunicación, acoger a los internos con calor y fraternidad, combatir la pasividad, estar abierto a las ideas y creencias de los otros, interesarse por el tiempo presente; debe fomentar la expresión, la creatividad, la iniciativa, la innovación, la toma de responsabilidad; ha de saber prever, organizar, ayudar al renacimiento del espiritu de comunidad por

(4) Viché Gonzảlez, M.; Ob, cit pág. 21 y ss. 


\section{Ciriaco Izquierdo Moreno}

medio de actividades culturales, sociales, recreativas, deportivas o por fiestas o celebraclones.

La persona del animador debe estar en posesión de una serie de cualidades; esto exige de él: aptitudes para captar la realidad en que actúa, despertar respuestas, acoger sugerencias,... unas aptitudes para la tarea que asume y una vasta información sobre la población o grupo con el que ha de trabajar en su acción dinamizadora.

En realidad, el animador es un lider con capacidad para conducir el grupo; un maestro capaz de poner al grupo en situación de concienclarse de su realidad y del protagonismo de su propia vida; es, por fin, un técnico con capacidad de gestión y dominio de los lenguajes técnicos;... el animador ha de tener una competencia cultural (contenido cultural y pedagógico) competencia relacional (capacidad de comunicación) y competencia técnica (saber utilizar instrumentos y técnicas adecuadas).

En el fondo, el animador sociocultural es un auténtico carismático, vive en una entrega vocacional permanente y vive los problemas desde dentro con un empuje y coraje no común para elevar y señalar metas nuevas a todos a quienes llega su mensaje, su contacto, su servicio (5).

(5) En uno de los próximos números de REVISTA DE FOMENTO SOCIAL, por el mismo autor y como continuación de este trabajo, publicaremos una amplia exposición de las experiencias de animación sociocultural en el Instituto Penitenciario de Liria (Valencia) a lo largo de los últimos veinticinco años. 